\title{
Preliminary Screening of Some Nutraceuticals as Aflatoxin (Aspergillus flavus) Reduction Agents Using In Vitro growth Inhibition Technique
}

\author{
Ari, M.M ${ }^{1}$., Hassan, D. I ${ }^{1,2}$. , Yakubu, $\mathrm{A}^{1}$.and Adua,M. $\mathbf{M}^{1}$. \\ ${ }^{1}$ Department of Animal Science, Faculty of Agriculture, Nasarawa State University Keffi, Shabu-Lafia Campus, Nigeria \\ ${ }^{2}$ Department of Animal Science, College of Agriculture, Science and Technology Lafia, Nasarawa State, Nigeria
}

\begin{abstract}
The following nutraceuticals: Moringa oleifera Lam., Garlic (Allium sativum) and Ginger (Zinger officinale) were screened for their possible use as Aflatoxin (Aspergillus flavus) reduction agents by extracting their photochemical constituent's using aqueous and methanol extraction which were used as inhibitors of $A$. flavus . The results showed the presence of tannins, steroides, cardiac glycosides, anthraquinone, flavonoids, alkaloids terpenes and saponins in all the tested nutraceuticals. Methanol extraction had highest concentration of the phytochemical constituents in each and the growth inhibition zone of $A$. Flavus showed that the extracts of Moringa oleifera leaves, Garlic (Allium sativum $\mathbf{L}$ ) and Ginger (Zingiber officinale) inhibit the growth of $A$. flavus in methanol extract, while aqueous extraction showed no zone of inhibition. The sensitivity results obtained revealed significant (p>0.05) difference on zones of inhibition at different concentrations of $12.5,25,50,100$ and $200 \mathrm{mg} / \mathrm{ml}$ of the extracts of Moringa oleifera leaves (A), Garlic (B) and Ginger (C) and for methanol extracts (A), (B) and (C) at concentration of $12.5 \mathrm{mg} / \mathrm{ml}$. The highest zones of inhibition is extract $(\mathrm{C})$ at $200 \mathrm{mg} / \mathrm{ml}$. The constituents in these nutraceuticals and the sensitivity results obtained indicates that these nutraceuticaals could be used as phytogenic feed additive for the inhibition of growth of mycotoxins in feeds
\end{abstract}

Keywords:- Nutraceuticals, Aflatoxin, Aspergillus flavus, Invitro,

\section{INTRODUCTION}

The contamination of foods and feeds with mycotoxins is a widespread phenomenon and thus providing ready access of mycotoxins reach to humans through food chain. The effect of ingested mycotoxins to human health varies from acute to chronic (Gbore, 2019). Similarly, Fung and Clark (2004) and Bunger et al. (2004) reported various health hazards caused by inhalation of dust containing mycotoxins. A variety of toxic effects associated with Aflatoxin contamination of the entire food supply chain is caused through post harvest activities and by inclusion of crops like maize and groundnut that are highly susceptible to infestation in monogastric diets.

Mycotoxin contamination of maize represents a widespread problem in the food and feed industries because maize can be easily contaminated by toxigenic mould such as Aspergillus and Fusarium species. These occur as either plant pathogens in the field or as the source of mycotoxin contaminants during storage as Aspergillus flavusis is one of the most abundant moulds that produce mycotoxins and contaminate human foods and animal feeds through fungal growth prior to and during harvest, or during improper storage (Binder, 2007; Ogara, et al., 2017; and Gbore, 2019).

The impact of aflatoxin toxicity resulting from intake of mycotixin infested foods especially maize in Nigeria was noted when significant quantities of aflatoxins were detected in breast milk, implicated in neonatal jaundice and growth retardation (Atanda et al., 2007; Bankole, et al., 2006; Oyelami et al., 1995) and the autopsy of brain tissues of children with kwashiorkor.

The use of some Nutraceuticals such as Moringa oleifera leaves, Garlic (Allium sativum) and Ginger (Zingiber officinale) to inhibit growth of microorganism and serve as important component of natural medical practices as the application of these herbs were reported to prevent morphological changes and oxidative damages to human and animals by enhancing the activities of antioxidant enzymes, reducing the density of lipid peroxidation and inhibiting generation of free radicals (Fanelli, et al., 1998; Ari et al., 2012 and Ari et al. 2019).

The basic assumption in the current study was that utilization of these nutraceuticals will have an inhibitory effect on the growth of mycotoxins in maize, thus the objective of this study is therefore to evaluate the phytochemical constituent's of the nutraceuticals using different extraction medium and screen their effects on isolate of Aspergillus flavus. This process is a prelude to incorporation into a maize base broiler diets.

\section{MATERIALS AND METHODS}

\section{$>$ Collection and Processing of Nutraceuticals \\ - Moringa oleifera Leave (MOL)}

Fresh Moringa oleifera leaves were harvested and airdried under room temperature to prevent the leaves from being denatured until they are crispy to touch for 5 days, later the crispy was milled into fine powder (50 grams) and stored separately in an air tight polyethene bag as reported (Terzungwe, 2013;Hassan et al., 2015; and Ari et al. 2019) 


\section{- Garlic (Allium sativum L) Bulb (GBM)}

Matured garlic bulbs were purchased from Vegetable Markets in Lafia, Nasarawa State. The scales around the fresh bulbs were removed while the bulbs were washed and rinsed properly in tap and sterile distilled water, respectively. The bulbs were sliced and ovum dried using hot ovum model DHG-9101- SA at the laboratory at $71^{\circ} \mathrm{C}$ for $48 \mathrm{~h}$. The ovum dried were grounded to smooth powder and stored in an air tight polyethene bag according to the methods described by Ari et al. (2012).

\section{- Ginger (Zingiber officinale) (GIM)}

Fresh ginger rhizomes were purchased from Lafia market, Nasarawa State. The cleaned rhizomes were chopped into tiny pieces and ovum dried in a hot ovum at $71^{\circ} \mathrm{C}$ for $48 \mathrm{~h}$. The materials are air dried and grounded to a smooth powder and stored in an air tight polyethene bag.

\section{> Phytochemical Screening of the selected Nutraceuticals}

The qualitative phytochemical analysis of the selected nutraceuticals were carried out using standard phytochemical techniques as described by Edeoga et al. (2005) and Oluduro (2012).

\section{$>$ Isolate of Aspergillus flavus.}

The fungus of the isolate of A. flavus was collected from the Department of Dematopyhilosis, National Veterinary Research Institute NVRI Vom where the fungus was then sub-cultured using Sabouraud Dextrose Agar medium at the Microbiology Laboratory, of the same institution.

\section{- Preparation of spore suspension of the fungus}

Two weeks old purified cultures of A. flavus (when mycelia had produced spores) were used for preparing spore suspension. The spore suspension was prepared by adding sterilized distilled water $(\sim 1 \mathrm{ml})$ to each Petri-dish containing the fungus culture to allow the spores to be suspended in the water. The spore suspension was then collected and quantified using a spore counter; the concentration values obtained were adjusted to $1 \times 10^{6}$ spore per millilitre.

\section{Assessment of anti-fungal activities of the Nutraceuticals}

Anti - fungal activities assessment was conducted using the paper disc diffusion method as described by Prabuseenivasan (2006). The assessments were done by measuring the growth inhibition zone of the fungus on Sabouraud Dextrose Agar medium. The extracts of MOL, GBM and GIM $\mathrm{mg} / \mathrm{ml}$ respectively of the nuturaceuticals were prepared by dissolving the required amounts in dimethyl sulfoxide (DMSO). To remove any microbial contamination, the extracts were filtrated by using twomicrometer filters (Millipore filter 2) before submerging some autoclaved paper discs (6 $\mathrm{mm}$ in diameter) in the prepared concentrations in sterilized distilled water and/or in 0.2 percent fungicide Mancozeb solution. The discs were allowed to be saturated with the solutions while the submerged paper discs were then air dried. Petri dishes containing Sabouraud Dextrose Agar medium were inoculated with $A$. flavus by transferring half a millilitre of spore suspension of the fungus $\left(1 \times 10^{6} \mathrm{spore} / \mathrm{ml}\right)$ and evenly spreading on the surface of the medium after which one paper disc loaded with each solution was placed in the centre of $A$. flavus inoculated Petri dishes.

The plates were incubated at $26^{\circ \mathrm{C}}$ in the dark. The average diametrical growth inhibition zone of A. flavus around the paper discs impregnated with each samples were measured for $7 \mathrm{~d}$ post inoculation until the plates were completely covered with mycelia of the fungus.

\section{Statistical analysis}

Data generated were subjected to one way analysis of variance and the means were separated using Duncans Multiple Range Test using SPSS software version 22

\section{RESULTS AND DISCUSSION}

The phytochemical evaluation as indicated in Table1 showed that the active constituents found in Moringa oleifera leaves, Garlic and Ginger the presence of tannins, steroides, cardiac glycosides, anthraquinone, flavonoids, alkaloids terpenes and saponins. These constituents differ in concentration between extractions medium. The extract for solvents methanol extract showed more number of constituents when compared with aqueous extract. This agrees with the report of Divya et al. (2016) who worked on the phytochemical composition of Garlic (Allium sativum), and the report of Chinwe et al. (2015) who reported more constituents in Moringa oleifera leaves in aqueous solvent than in methanol extract. Similarly, more phytochemical constituents were extracted using methanol. These bioactive constituents in Moringa oleifera leaves, Garlic and Ginger have been used in the treatment of many diseases and disorders (Shipra et al., 2012; Chinwe et al., 2015; Divya et al., 2016) as well as in the development of resistance against microbial pathogens

The results in (table 2) shows zones of inhibition at different concentrations of $12.5,25,50,100$ and $200 \mathrm{mg} / \mathrm{ml}$ of the extracts of Moringa oleifera leaves (A), Garlic (B) and Ginger $(\mathrm{C})$. the results showed a significant $(\mathrm{P}<0.05)$ difference among the three nutraceticals and the concentration levels whilst methanol extracts (A), (B) and (C) at concentration of $12.5 \mathrm{mg} / \mathrm{ml}$ showed for extract (A) zones of inhibition $(\mathrm{mm}) 1.70 \pm 0.01$ followed by extract (C) with $1.60 \pm 0.01$ while the least zone of inhibition is extract (B) with $1.10 \pm 0.01$ at $25 \mathrm{mg} / \mathrm{ml}$. Methanol extracts (A) $1.80 \pm 0.01$ has the highest zones of inhibition while the least has $1.35 \pm 0.01$.

At $50 \mathrm{mg} / \mathrm{ml}(\mathrm{A})$ and $(\mathrm{B})$ has the highest $1.80 \pm 0.01$ zones of inhibition $(\mathrm{mm})$ each while the least is $(\mathrm{C})$ with $1.60 \pm 0.01$, However with increase at $100 \mathrm{mg} / \mathrm{ml}$ methanol extract $(\mathrm{C})$ has the highest zone of inhibition of $1.95 \pm 0.01$ followed by methanol extract of (A) while the least zone was extract of (B). The highest zones of inhibition is extract (C) with $2.65 \pm 0.01$ at $200 \mathrm{mg} / \mathrm{ml}$ followed by extract $(\mathrm{A})$ $2.60 \pm 0.01$ while the least zones of inhibition was extract (B) $1.95 \pm 0.01$. 
The results also revealed that all the aqueous extracts $\mathrm{A}, \mathrm{B}$ and $\mathrm{C}$ of the nutraceuticals showed no inhibition zones. These indicate that aqueous extracts did not have any positive inhibitory effect and therefore only methanol extracts of the nutraceuticals have significant impact on the mycotoxins. Similar constituents extracted from these nutraceuticals were reported to be used for the treatment and prevention of various diseases and disorders in both human and animal food and feeds (Mikail, 2010; Tiwari et al., 2011; Shipra et al., 2012).

The growth inhibition zone of A. flavus shown in (fig.1) indicated that the extracts of Moringa oleiferaleaves, Garlic (Allium sativum L) and Ginger (Zingiber officinale) inhibit the growth of A. flavus in methanol extract, but no zone of inhibition in aqueous extract was noticed. This is in agreement with the reports of Jafar and Sahar (2015) who used essential oil of Thymus eriocalyx on the growth of $A$. flavus and Jun et al.(2012) who use the essential oil extracted from the bark of Cinnamomum jensenianum for the same objective.

\section{CONCLUSION}

The inhibitory effects of the methanol extracts of the nutraceuticals studied indicates the possibility of their use as alternative prebiotic control of A. flavus which are often associated with deterioration and contamination due to storage conditions and other activities on grains and commercial poultry feeds.

The results of this investigation show that methanol extraction of ginger (Zingiber officinale) at $200 \mathrm{mg} / \mathrm{ml}$ concentration has the best inhibitory effect on the growth of A. flavus among the three nutraceuticals.

\begin{tabular}{|c|c|c|c|c|c|c|}
\hline \multirow[t]{2}{*}{ Parameter } & \multicolumn{2}{|c|}{ Moringa oleifera leaves } & \multicolumn{2}{|l|}{ Garlic } & \multicolumn{2}{|l|}{ Ginger } \\
\hline & Aqueous & Methanol & Aqueous & Methanol & Aqueous & Methanol \\
\hline Tannins & + & + & + & - & - & + \\
\hline Steroids & + & + & + & + & + & - \\
\hline \multicolumn{2}{|c|}{ Cardiac glycoside+ } & + & + & + & + & + \\
\hline \multicolumn{2}{|c|}{ Anthraquinone+ } & - & - & + & - & + \\
\hline Flavonoids & + & + & + & + & + & + \\
\hline Alkaloids & + & - & + & & - & + \\
\hline Terpenes & + & + & + & + & + & + \\
\hline Saponins & + & + & + & & - & + \\
\hline
\end{tabular}

+ indicated presence, - indicated absent

Table 1:- Phytochemical Constituents of Some Nutraceuticals 


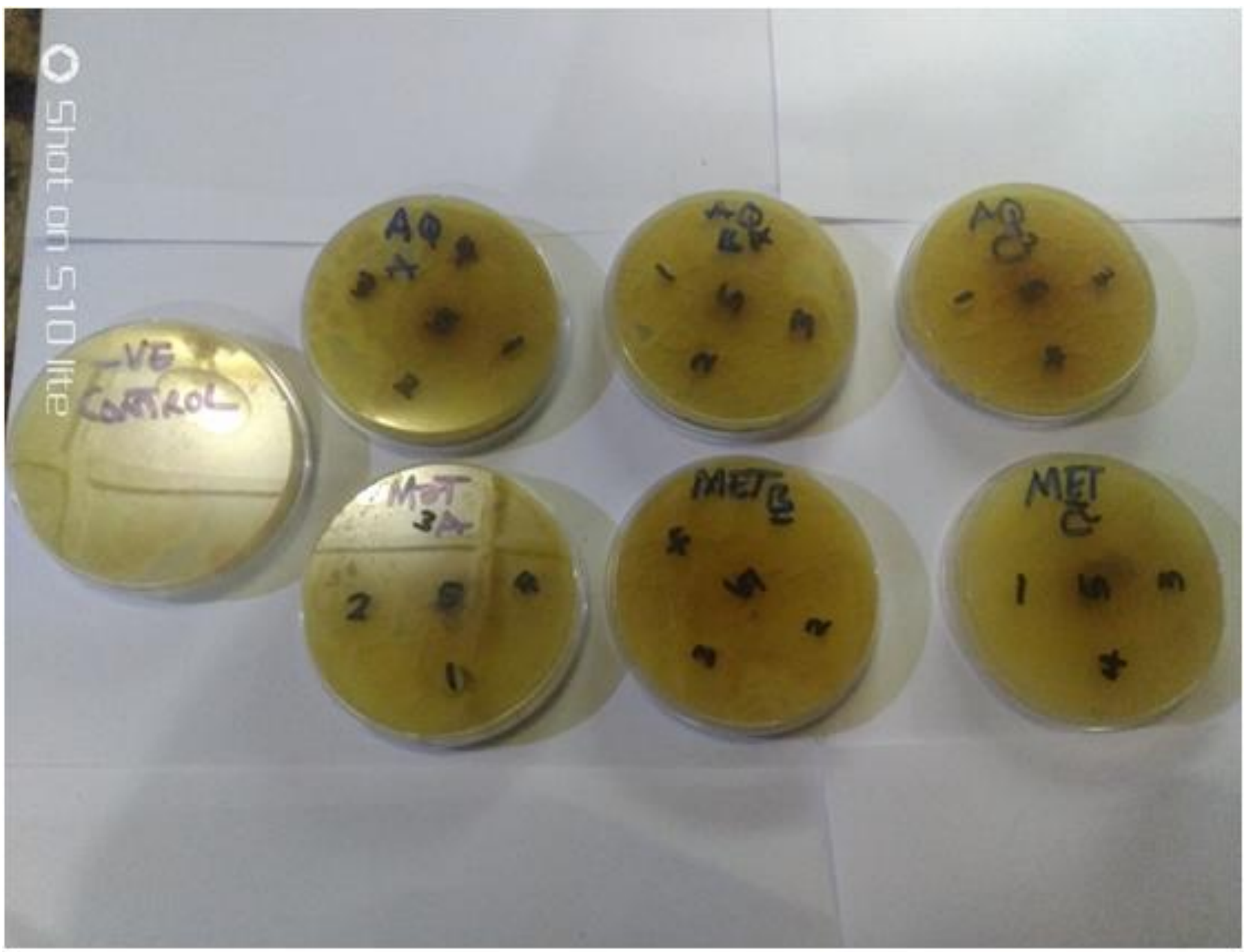

Fig 1:- The Invitro growth inhibition zone of Aspergillus flavus onSabouraud Dextrose Agar medium resulting from treatment of the fungus with $12.5,25,50,100$ and $200 \mathrm{mg} / \mathrm{ml}$ extracts of methanol and aqueous of Moringa oleifera leaves (A),Garlic (B) andGinger $(\mathrm{C})$.

\begin{tabular}{|c|c|c|c|c|c|}
\hline \multirow{2}{*}{ Sample extract } & \multicolumn{4}{|c|}{ Concentration/Zones of inhibition (mm) } & \multirow[b]{2}{*}{200} \\
\hline & 12.5 & 25 & 50 & 100 & \\
\hline Meth. Extract of (A) & $1.70 \pm 0.01^{\mathrm{a}}$ & $1.80 \pm 0.01^{\mathrm{a}}$ & $1.80 \pm 0.01^{\mathrm{a}}$ & $1.55 \pm 0.01^{b}$ & $2.60 \pm 0.01^{b}$ \\
\hline Meth. Extract of (B) & $1.10 \pm 0.01^{\mathrm{c}}$ & $1.60 \pm 0.01^{b}$ & $1.80 \pm 0.01^{\mathrm{a}}$ & $1.20 \pm 0.01^{\mathrm{c}}$ & $1.95 \pm 0.01^{\mathrm{c}}$ \\
\hline Meth. Extract of (C) & $1.60 \pm 0.01^{b}$ & $1.35 \pm 0.01^{\mathrm{c}}$ & $1.60 \pm 0.01^{\mathrm{a}}$ & $1.95 \pm 0.01^{\mathrm{a}}$ & $2.65 \pm 0.01^{b}$ \\
\hline Aq. Extract of (A) & - & - & - & - & - \\
\hline Aq. Extract of (B) & - & - & - & - & - \\
\hline Aq. Extract of (C) & - & - & - & - & - \\
\hline Significant & $\div *$ & $\forall *$ & $\therefore *$ & $\therefore *$ & $\therefore *$ \\
\hline
\end{tabular}

Table 2:- Sensitivity results showing zones of inhibition at different concentration

abc Means on the same column bearing different superscripts are significantly different at $(\mathrm{P}<0.05)$, Means inhibition $(\mathrm{mm}), \pm$ standard error of mean, - no inhibition, **significant at 95\%, Meth. (Methanol), Aq.
(Aqueous),Moringa oleifera leaves (A),Garlic andGinger $(\mathrm{C})$ 


\section{ACKNOWLEDGEMENT}

This study was funded from the Nigerian government Tertiary Education Trust Fund (TETFUND) research grant awarded to Maikano Mohammed Ari of the Department of Animal Science, Faculty of Agriculture, Nasarawa State University, Keffi, Shabu-Lafia Campus in 2019; and is gratefully acknowledged. Special thanks to all the Staff of the Faculty and NVRI Laboratories that were involved in the project.

\section{REFERENCES}

[1]. Ari, M. M. , Barde R . E., Ogah, .D M., Agade,Y.I, Yusuf ,N.D, Hassan, I.D and

[2]. Muhammed,M.M (2012) Utilization Of Garlic (Allium Sativum L) As A Supplementary Phytogenic Feed Additive For Broilers Fed Commercial Feeds Egypt. Poult. Sci. 32 (I): (13-21)

[3]. Ari, M.M, Idahor, K.O, Mohd, M.S, Iheidu B.N, Ogah , D.M and Adigizi, E.A (2019)

[4]. Utilization of garlic, tigernut, amaranthus and baoba leavesas nutraceuticals to boost Nera Black performance and egg quality Journal of Biomater 9:

[5]. Atanda, O., Oguntubo, A., Adejumo, O., Ikeorah, J., andAkpan, I. (2007). Aflatoxin M1 contamination of milk and ice cream in Abeokuta and Odeda local governments of Ogun State, Nigeria. Chemosphere. 68: $1455-1458$

[6]. Bankole, S. A., Ogunsanwo, B. M., Osho, A., andAdewuyi, G. A. (2006). Fungal contamination and aflatoxin B1 of Egusi_melon seeds in Nigeria. Food Control. 17: 814-818.

[7]. Binder, E. M. (2007). Managing the risk of mycotoxins in modern feed production. Animal Feed Science Technology. 133:149-166.

[8]. Bunger, J., Westphal, G., Monnich, A., Hinnendahl, B., Hallier, E., and Muller, M. (2004). Cytotoxicity of occupationally and environmentally relevant mycotoxins. Toxicology, 202: 199-211.

[9]. Chinwe, C. I., Maria, J. S., Carmita, J. J. and Fausto, D. (2015). Phytochemical and Nutritional properties of dried leaf powder of Moringa oleifera Lam. Form Machala el oro province of Ecador. Asian Journal of Plant Science and Reseach. 5(2):8-16.

[10]. Divya, B. J., Suman, B., Venkataswamy, M. and Thyagaraju, K. (2017). A study of phytochemicals, functional groups and mineral composition of Allium sativum (Garlic) cloves. Int. J. curr. Pham. Res, Vol 9, Issue 3, $42-45$.

[11]. Duncan, D.B., (1955): Multiple ranges and multiple Ftest. Biometrics 11, 1-42.

[12]. Edeoga, H. O., Okwu, D. E., andMbaebie, B. O. (2005). Phytochemical constituents of some Nigerian medicinal plants. African Journal of Biotechnology. 4 (7): 685-68.

[13]. Fanelli, S. L., Castro, G. D., De Toranzo, E. G., and Castro, J. A. (1998). Mechanisms of the preventive properties of some garlic components in the carbon tetrachloride-promoted oxidative stress. Diallylsulfide; diallyldisulfide; allylmercaptan and allyl methyl sulfide. Res. Commun. Mol. Pathol. Pharmacol. 102: 163-174.

[14]. Fung, F., and Clark, F. R. (2004). Health effects of mycotoxins: A toxicological overview. J. Toxicol. Clin. Toxicol.,42: 217-234.

[15]. Gbore, F. A. (2019). More than a conqueror: the battle against the siege of mycotoxins. $12^{\text {th }}$ Inaugural lecture delivered at AdekunleAjasin University, AkungbaAkoko, Ondo state, Nigeria.

[16]. Hassan, D. I., Aya, V. E., Alaku, A. I., Musa, S. I., Barde, R. E., Adua, M. M., and N. D. Yusuf. (2015). Effects of Moringa oleifera leaves on Body weight and Haematological parameters of Rabbits infected with Trypanasomacongolence.PAT.11 (2): 253-259 ISSN:

0794-

5213.www.patnsukjournal.net/currentissue.

[17]. Jafar, N. and Sahar, G. (2015). Invitro growth inhibition of Aspergillus flavus, a major aflatoxin producing fungus, using Thymus eriocalyx essential oil. ScietiaAgriculturae. 10 (3): 110-114.

[18]. Jun, T. B. H., Xiuli, L., Hong, Z., Xiaoquan, B., Jingsheng, H. and Youwei, W. (2012). The control of Aspergillus flavus withCinnamomumjensenianum. Hand-Mazz essential oil and its potential use as food preservatives Food chem. 130 (3): 520- 527.

[19]. Mikail, H. G. (2010). Phytochemical screening element, elemental analysis and acute toxicity of aqueous extract of Allium sativum L. bulbs in experimental rabbits. J. Med. Plants Res.4:322-6.

[20]. Oluduro, A. O. (2012). Evaluation of antimicrobial properties and nutritional potentials of Moringa oleifera Lam. leaf in South Western Nigeria, Malaysian Journal of Microbiology, 8 (2): 59-67.

[21]. Oyelami, O. A., Maxwell, S. M., Adelusola, K. A., Aladekoma, T. A., andOyelese, A. O. (1995). Aflatoxins in the autopsy brain tissue of children in Nigeria. Mycopathologia, 132 (1): 35-38.

[22]. Prabuseenivasan, S., Jayakumar, M., andIgnacimuthu, S. (2006). In vitro antibacterial activity of some plant essential oils. BMC Complement Alter Med 6(39): 18.

[23]. Shipra, B., Kshira, D., Amla, B., Asha, S. and Bharti, M. (2012). Zingiber officinale: Chemical and phytochemical screening and evaluation of its antimicrobial activities. Journal of chemical and Pharmaceutical research. 4 (1): 360 -364.

[24]. Terzungwe, A., Adakole, H. A., and Lois K. I. (2013). Physiological Responses Of Rabbits Fed Graded Levels Of Moringa Oleifera Leaf Meal (MOLM): Some Aspects Of Haematology And Serum Biochemistry. Archives of Applied Science Research, 5 (2):172-176.

[25]. Tiwari, P., Kumar, B., Kaur, M., Kaur, G. and Kaur, H. (2011). Phytochemical screening and extraction: A review, International PhamaceuticaSciencia 1 (1):98106. 